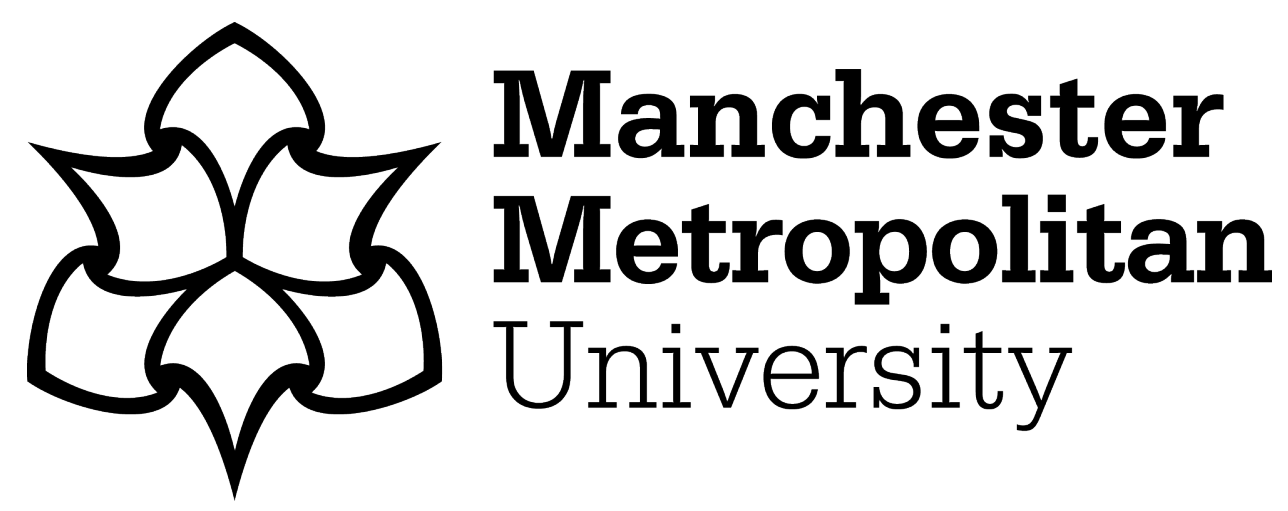

McKenzie, Chloe and Tarpey, Emma ORCID logoORCID: https://orcid.org/0000-0003-2238-2719 (2019) Exploring forensic service users' experience of participating in a community life skills and workreadiness programme. Journal of Forensic Practice, 22 (1). pp. 1-11. ISSN 2050-8794

Downloaded from: https://e-space.mmu.ac.uk/625093/

Version: Accepted Version

Publisher: Emerald

DOI: https://doi.org/10.1108/jfp-05-2019-0020

Please cite the published version 


\title{
Exploring Forensic Service Users Experience of Participating in a Community Life Skills and Work-readiness Programme.
}

\author{
Abstract \\ Purpose - The purpose of this paper is to provide insight into the experiences of individuals with a \\ criminal history of participating in a community life skills and work-readiness programme. \\ Design/Methodology/approach-Semi-structured interviews were conducted with seven individuals \\ that have a criminal history who were participating, or had previously participated, in a community \\ life skills and work-readiness programme. This data was analysed by interpretative \\ phenomenological analysis.
}

Findings- Four superordinate themes emerged, these were: "need to change", "changing identity", "giving back to the community" and "a sense of belonging". These themes are discussed in relation to desistance literature and the Good Lives Model.

Practical implications - This research identifies through the participants narratives that engaging with the programme appeared to facilitate the desistance process. The importance of community programmes that provide participants skills and social integration must be acknowledged.

Originality/value - There is limited research on the experiences of forensic services users' experiences of community programmes, especially those that are not aimed specifically at exoffenders. The results of this research can be used to enhance services and identify further research areas.

Keywords Desistance, Good Lives Model, Interpretative Phenomenological Analysis, Community, Offenders, Identity

\section{Introduction}

The Prison Reform Trust (2018) argues that prison has a poor record for reducing reoffending, evidenced by the recidivism rates for individuals released from prison. Reoffending data indicates that $37.2 \%$ of adults released from custody reoffend within one year of release (Ministry of Justice and National Statistics, 2019). It has been recognised by the Ministry of Justice (2013) that reoffending rates have remained stubbornly high for too long, and providing individuals with a criminal history a 'second chance', is in the best interests of society, as this can improve life chances (DWP and MOJ, 2016). This is reflected in the Government's aim to support offenders to become more productive members of society (HM Government, 2005). When supporting individuals to desist from offending, particularly when recently released from prison, it is crucial to consider a variety of factors that influence the desistance process and it is recognised that this involves a complex interaction between both subjective, and environmental factors (Lebel et al., 2008).

The strengths-based approach to offender rehabilitation focuses on developing an individuals' competencies and skills, which contributes to a reduction in recidivism, one such approach is the Good Lives Model (GLM) (Fortune et al., 2012). The GLM was developed by Ward (2002) and argues that rehabilitation should identify the external and internal conditions necessary for an individual with a criminal history to achieve primary human goods, such as excellence in work and play, excellence in agency, and community. It seeks to provide those who have offended with opportunities to secure primary human goals through socially acceptable and meaningful ways (Ward and Brown, 2004). 
The development of the GLM has involved an alignment with desistance theory (Ward and Maruna, 2007). Desistance from crime occurs when individuals with a criminal history re-assess their lives (Terry, 2003), and are provided with the skills, opportunities, resources and knowledge to live a 'good' life (Ward and Maruna, 2007). Maruna's (2001) study compared individuals with a criminal history that were desisting from crime with active offenders, and identity was identified as crucial in the desistance process. For individuals with a criminal history, creating a new identity involves internalising the values of a good life, as the perceived ability to gain primary goods is closely linked with personal identity (Ward, 2002). Community was also an important factor identified by Maruna (2001), in terms of giving something back to the community; the need to be a part of a community has also been identified as a primary good in the GLM (Willis et al., 2013). These findings indicate the importance associated with community integration for individuals that are moving away from a life of crime.

Reintegration to the community for offenders is supported by securing employment, as this allows offenders to successfully fulfil pro-social roles that are viewed as important to integration (Cherney and Fitzgerald, 2016). It is recognised that employment acts as a positive source of change for individuals embarking on a desistance journey (Laub and Sampson, 2003). Therefore, finding stable employment has been recognised as a strong predictor of post-release success (Visher et al., 2005). However, many offenders experience difficulty in obtaining and maintaining employment (Newton et al., 2018). This is linked to the various barriers that offenders encounter which include stigma as a result of imprisonment, substance misuse, social isolation and low educational attainment (Talbot et al., 2017). To support ex-offenders to obtain and maintain employment, a variety of work-readiness programmes have been developed. Work-readiness refers to equipping individuals with the skills and confidence required to gain and sustain employment (Ford et al., 2015). It is recognised that relatively little is known regarding training programs, such as work-readiness schemes, impact on reoffending (Newton et al., 2018). Newton et al (2018) identified that programmes that adopt a holistic and comprehensive approach, through providing support on factors that may impact on an offender's reintegration into the community are deemed more promising than those that focus solely on employment. It is also recognised that work-readiness programmes should provide personal support and consideration should be provided to the individual's motivation and readiness to work (Ford et al., 2015).

\section{The present study}

This research aimed to explore the experiences of individuals with a criminal history that had completed, or were taking part in a charity provided, community life skills and work-readiness programme. The objective of this research was to explore the key factors of the programme that facilitated the participants desistance journey. The charity aims to support individuals in the community that are at risk of homelessness and whom are facing barriers in their life such as longterm unemployment, mental health issues or a criminal record. The individuals that participate in the programme complete voluntary work for a period of five months. Alongside the volunteering, the participants are able to take part in additional courses and activities that are delivered by the charity, whilst being supported by the programme staff. As this research focuses upon the experiences of the individuals with criminal histories participating in the programme, a qualitative approach was implemented, specifically interpretative phenomenological analysis. IPA allows for the way participants make sense and the meaning of experiences to be examined (Smith and Osborn, 2007).

\section{Method}




\section{Participants and Recruitment}

Individuals that had previously completed, or were taking part in the programme were recruited to participate in this research via purposive homogeneous sampling. The inclusion criteria consisted of participants having been on the programme for at least a month, be aged 18 or over, and have a criminal history. Approximately 80 participants engage with the programme at one time with around $10 \%$ of these individuals having a criminal background. The programme coordinator identified and contacted potential participants. Seven suitable participants were identified and recruited to take part in the research. The participants were male, aged between 23 and 55 years. Six participants discussed having been sentenced to prison previously. The duration of time spent in prison varied among the participants, some had been imprisoned multiple times for shorter sentences and three discussed spending a long duration in prison. The main offences committed by the participants included supplying drugs and violence. All of the participants had a previous history of substance misuse.

\section{Procedure}

A semi-structured interview schedule was created, and each participant was interviewed for approximately 45 minutes. The interview schedule followed the guidelines outlined by Smith and Osborn (2007). The topics for the interview schedule were guided by existing research (Lebel et al., 2008; McNeil et al., 2005; Maruna; 2001 Ward and Brown, 2004; Ward and Maruna, 2007) and included: before the programme; motivation/involvement; identity; support; and community integration. The interviews were audio-recorded and transcribed by the primary researcher.

\section{Ethics}

Permission to conduct the research and interview participants was provided by the management of the charity. Manchester Metropolitan University granted ethical approval. To ensure anonymity the participants were given pseudonyms. Each participant gave informed consent before taking part in interviews. There was consideration regarding sharing the participants' criminal history with the primary researcher. Therefore, the participants were not required to share their offence history to take part in the research. Participants were made aware of their right to withdraw from the research.

\section{Data analysis}

Interpretative phenomenological analysis (IPA) was employed to gain insight into the participants' experiences and meanings of the programme. The IPA approach to psychological qualitative research has an idiographic focus; therefore it offers insight into how the participants of the research make sense of a particular phenomenon (Smith et al., 2009). How the participants make meaning of their life experiences is pertinent to the IPA approach (Smith and Osborn, 2007). As this research has a focus upon how the individuals with a criminal history participating in the programme have perceived the programme and their experiences, IPA was deemed a suitable approach.

The IPA technique recommended by Smith et al (2009) was followed to develop superordinate and subordinate themes. This involved the primary researcher immersing oneself in the original data through reading and re-reading the data. The next stage involved making initial notes, including descriptive, linguistic and conceptual comments. Following this, themes were developed and connections across themes were identified. The development of themes went through a stage of triangulation. This involved a discussion with the second author on the themes developed from the raw data. 


\section{Results and discussion}

Four superordinate themes emerged from the interpretative phenomenological analysis. Table 1 displays the superordinate themes and the corresponding subordinate themes, and the shaded cells identify the participants that the theme was present for.

Table 1: Superordinate and subordinate themes and the presence for each participant

\begin{tabular}{|c|l|l|l|l|l|l|l|}
\hline 1. Need to change & Tyler & Mark & George & Joe & Ivan & Kevin & Will \\
\hline $\begin{array}{c}\text { 1.1 too much time on anybody's } \\
\text { hand brings out the devil }\end{array}$ & & & & & & & \\
\hline 1.2 Distancing from old friends & & & & & & & \\
\hline 2. Changing Identity & & & & & & & \\
\hline 2.2 Free from all my demons & & & & & & & \\
\hline 2.3 Looking to the future & & & & & & & \\
\hline 3. Giving back to the \\
community
\end{tabular}

\section{Need to change}

This theme contributes a foundation for understanding the participant's reasons and motivations for initially engaging with the programme. The participants' narratives reflect that participation occurred as a result of a view that there was a need to change.

"My life needed a change, my life needed uprooting and sorting back out" (Tyler: Line 28)

"I reached that point in my life where I wanted to change. I tried to do it in the past to try and keep people happy but it doesn't work that way, you need to feel that you need that change as well" (Joe: Line 37-39)

The narratives indicate the importance of an active choice to change. Joe shows a strong desire of wanting the change himself. This reflects that the first step of desistance identified by Giordano et al (2002) was occurring, which involves awareness that change is desirable and needed. 
The participants provided different explanations for their need to change, which are highlighted by the subordinate themes of "too much time on anybody's hands brings out the devil", and "distancing from old friends".

\section{Too much time on anybody's hand brings out the devil}

Participants expressed that before attending the programme they had too much free time and that they were not participating in society, with narratives reflecting a lack of social integration. George discussed the implications of having too much free time:

"this helps by basically keeping me occupied and busy because basically if it hadn't l'd probably be dwelled up, feeling sorry for myself, thinking sod it, sod the lot, sod the law, sod life, sod everything, Lets go and get pissed, which then leads me into that vicious circle again." (Line 286-288)

"too much time on anybody's hands brings out the devil does it not" (Line 296)

The impact of imprisonment on opportunities to engage in prosocial activities is expressed in Will's account:

"I was struggling anyway because after being released I was in a hostel and I was struggling to adapt back into society anyway but to have nothing to do anyway as well, so alright now what do I do?" (Line 16-18)

Both George and Will expressed the problem of having too much free time, which appears to be tied with a lack of social integration. This was also identified in Kevin's narrative:

"I was not participating in anything what so ever" (Line 2)

A lack of social integration is particularly salient when the individual has been imprisoned, as custodial sentences often isolate ex-prisoners from their communities and fellow citizens (Uggen et al., 2004). Ford et al (2015) found that individuals volunteered with charities as they viewed it as an opportunity for them to do something meaningful with their time and this supported them to maintain a distance from their previous lifestyles. This finding is reflected within the current research as participating in the programme facilitated productive use of the participants' time.

\section{Distancing from old friends}

Many participants viewed distancing themselves from old friends as being crucial to creating a lawabiding life. The participants also highlighted the challenges that came with this:

"I felt like it was time to hit the hard reset and basically and for me that was a quite hard thing to do because it meant cutting off all my ties" (Tyler: Line 29-30)

For Tyler the aspect of becoming a law-abiding individual was intertwined with distancing himself from people that have been in his life. Tyler also used an analogy to describe how the people he was surrounding himself with in his past wanted to "anchor" him. These people would hold him back, describing these people as "toxins". However, cutting ties was not without difficulties, as expressed by Tyler:

"I wanted to meet new people obviously as I just said I cut a lot of people and that left me very lonely. Yeah. So obviously I had to refill that gap in my life" (Line 123-124)

By engaging in the programme, Tyler was also able to counteract the impact that "cutting off" his old ties. 
Will also discussed how he had to distance himself from his old friends and expressed concerns about having contact with them and about the feelings that this may evoke:

“[...] I didn't want to see my like old sort of associates because I didn't know what sort of feelings it would bring up in me like cause I can imagine they're still on drugs, I can imagine they're still living an unhealthy lifestyle and all that and if I was to see them now how would I feel, what would I say and all that" (Line 126-129)

Kevin emphasised the lack of connection with his past associates:

"I just don't bother with people I used to bother with, because they're not really your mates, you know what I mean, just associates what you got mixed up in" (Line 125-127)

The experiences of the participants supports the social identity framework (Ellemers et al., 2002) illustrating that the participants were motivated to exit their unfulfilling group membership, replacing it with a more meaningful membership. This supports that removing ties with anti-social others is crucial for desistance from crime (Bryne and Trew, 2008). The participants' narratives indicate that distancing themselves from their old associates led to challenges, however that the programme supported them through managing this transition.

\section{Changing identity}

This theme describes how perceived changes in identity occurred for the participants, and the importance the participants placed upon their changed identity. Maruna (2001) found that for individuals to be able to desist from crime it is essential that they develop a pro-social identity. This theme incorporated the subordinate themes of "free from all my demons" and "looking to the future".

\section{Free from all my demons}

It was apparent through the participants' narrative that they distinguished between their past experiences, and their current lives. The participants' past experiences involved trauma, hitting rock bottom and crisis of identity. This was evident within Ivan's narrative:

"I was suffering from depression for a long while. I was trying to wean myself off the heroin but I was finding it very difficult [...]. So you know I was prepared to just not be here. My life had no existence. It was just drugs. I couldn't get myself off it. So erm. I wanted to die. I just wanted to die. I wanted to find a way to not be here."(Line 16-17, 24-26)

"I used to say to myself, inside to myself, when I'm 50 I won't be here. You know something, now I'm 50 , I've got past 50, I look back and I say well I did die but I reborn again, I reborn again. I came back a different person. [...] And also the most important thing, I'm free. I'm free from all my demons. Free far gone." (Line 129-131, 133)

When Ivan compares his past to the present he acknowledges the challenges he has overcome with particular reference to his "demons". The change in identity is such a significant shift for Ivan that he likens this to birth and death, and described being "reborn", clearly defining a new identity for himself:

"I never used Ivan. Whilst in (the charity) I used that name Ivan. Yeah, it's made me a different person. It's made me Ivan you know what I mean" (Line 223-225)

This distinction from past experiences is also described by Mark, as he attempts to explain his current and former self: 
"I didn't even know what type of person I was because even when I was doing nasty things I was like wow this ain't right, but I still carried on being nasty. I just couldn't help it" (Line 40-41)

"[...] I think I've got a lot more to give, as before I thought I was just existing to be honest getting on day by day." (Line 92-93)

Through participation in the programme the participants were able to distance themselves from their past experiences allowing them to have more control over their lives and be able to create a new identity. This is reflected by Aresti et al's (2010) research findings that this self-change liberated the individuals, freeing them from restrictive previous experiences. It is recognised that a key feature for individuals desisting from crime is the discovery of the true self (Paternoster and Bushway, 2009). The GLM views that for individuals with a criminal history it is essential they are provided with the opportunity to gain a more adaptive personal identity, providing a sense of meaning and fulfilment (Ward and Maruna, 2007).

\section{Looking to the future}

Participants' viewed that their self-worth and confidence improved by engaging with the programme. Many individuals discussed their future of a life without crime, which often incorporated gaining employment. The programme allowed participants to recognise their skills, gave them optimism and confidence to use these skills to live a pro-social life:

"I don't believe I've gained skills, I believe I've improved, yeah. I believe I've re-tapped into the skills I already had" (Tyler: Line 304-305)

"my confidence grew and I just loved it. I was just, I think it was just I was glad to find me again. It opened me up really" (Joe: Line 192-193)

Participants expressed difficulties they had experienced in gaining employment, which they perceived as being due to past imprisonment, however the programme had helped to overcome this:

"I've got a big gap in my C.V. So if I went to an employer they'd say why is there such a big gap in your C.V. I've been in prison what for [...] this employer now will think he's at the (charity) doing voluntary work that says a lot about someone" (Kevin: Line 140-142, 159-160)

"It stands me in good stead if I want to get a job at some point, l'll be almost used to doing work." (Will: Line 22-23)

The narratives indicate how participation in the programme was considered by participants as a way to overcome the barriers that they may encounter in the future. Through the narratives, it can be viewed that the importance of money is not the most important aspect they may gain. This is similar to Kirby's (2016) research that found that young offenders taking part in employment very rarely spoke about the link between volunteering and gaining employment, rather they spoke highly of the softer skills they gained. It has been previously recognised that an accomplishment for ex-offenders, such as engaging in a programme, can lead to a sense of hope and an orientation towards the future (Richie, 2001). It is recognised that during the process of desistance, individuals adopt a belief that they can succeed, involving a high degree of optimism and control over their future (Maruna, 2001).

\section{Giving back to the community}

For all participants giving back to the community was an important part of participating in the programme: 
"It was just to help really, just to give back. Because I do like helping people." (Line 63)

For the majority of the participants their own experiences influenced the importance of giving back to the community. Participants discussed that they in the past have experienced similar difficulties in their lives to the client group of the charity. This is reflected these participants' narratives:

"It makes me feel good almost, as if I'm putting something back because many years ago there was a few people helping me. So it feels good to be putting even the slightest thing back and in any kind of way trying to help someone else. (Will: Line 5-8)

"I think it's just helping people that can't cope really and struggling. Even I've struggled before, before I moved when I lived on my own I've had to use the food bank and I felt horrible having to go, it didn't feel right. So I know what it's like" (Joe: Line 222-224)

It appears that the participants were able to gain a sense of purpose and fulfilment through the work they did, with particular importance being placed on helping others. This reflects Maruna's (2001) findings that individuals desisting from crime wanted to help others as they had received such help themselves and that having a sense of giving something back to community for individuals moving to a life without crime is of great importance. A positive identity is then created through the actions of being able to make a positive contribution to local communities (McNeil et al., 2005).

\section{For self or others}

Within the narratives it was apparent that the participants felt difficulty distinguishing whether their motivations for volunteering were altruistic or egotistic.

“[...] its like you don't get nowhere unless you're helping other people, I think cause your helping yourself at the end of the day" (Kevin: Line 29-30)

"I have been homeless myself so I did want to give something back, I did want to help that service out yeah, so a lot of it was that. In the same breathe, I am looking out for number one out here. I was using the voluntary experience to enable me to get into work."(Tyler: Line 118-120)

"I was just doing it at the time for myself because I had to do it for myself. And as I went on I was doing it for myself and for others" (Mark: Line 53-54)

The participants show an understanding that the voluntary work is helping them with their personal enhancement and career benefits, yet it appeared that they felt that they needed to also discuss motivations in relation to helping others and giving back to the community. It is also interesting to note that Will felt that he was unlikely to make a difference in the community:

"I know no matter what I do in here it can't help the homeless people but it helps me" (Line 4-5)

Aresti et al's (2010) research identified that ex-offenders experience an ongoing tension related to their sense of self; it was perceived that the participants had internalized society's negative view of ex-offenders, as well as having an interweaving view of self, based on having a previous offender status. In line with such findings, it is speculated that for Will, he may be unconsciously flitting between having a pro-social view of self, involving helping others, and then his previous criminal view of self. When viewing himself in relation to his previous criminal self, it would be likely that Will views himself as not being capable of helping others, which would be influenced by the stigma and negative view of offenders being internalised.

\section{A sense of belonging}


This theme captures the importance that the programme had in terms of social integration. The importance of the sense of belonging was apparent when individuals were asked what the most important part of the programme was for them:

“a sense of belonging, as before I didn't feel like I belonged anywhere" (Mark: Line 390)

"I think just being a part of it. [...] Being involved" (Joe: Line 241 and 243)

"being a part of something, just being a part of something. And that's the main thing, you feel a part of something. You're not just a number or a victim or whatever the word is. You felt a part of something." (Ivan: Line 203-204)

Ivan's narrative suggests that the belonging helps people to move away from being a number or a victim. Maruna and LeBel (2003) indicate that reintegration can be difficult for individuals with a criminal history, therefore it is recognised that individuals with a criminal history often have a need to be a part of a social network and the community in order to facilitate the desistance process. It is also recognised that belonging to a group encourages internalisation of values and norms, which supports positive change (Best et al., 2018)

This theme incorporates the subordinate theme "the teams as strong as its weakest link".

\section{The teams as strong as its weakest link}

Throughout the narratives the experience of participants supporting one another is described. It was apparent that participants felt that this was an important element of the programme:

"it's not just the coordinators it's the other participants and everything, all of them incorporate into the environment, yeah. I'll use another saying, yeah, a team is only as strong as its weakest link. [..] Everyone is pushing everyone else to go higher. There is hardly any anchors within (the charity)" (Tyler: Line 279-283)

"You have to work as a team. There's an old expression, the teams as strong as its weakest link" (George: Line 229-230)

The use of the saying "the teams as strong as its weakest link" indicates strong feelings of participants supporting one another and everyone being a part of a team. Tyler describes how by participants supporting each other that they encourage one another to go further. Will reiterates this as he discussed that:

"it's just everybody pulling in the same direction what makes it work" (Line 367)

Through analysis of the narratives it was clear that participants were often thinking of each other, as they often discussed their experience in relation to other participants on the programme, considering their experiences and what they have been through, and wanting to provide others with support. These strong social bonds developed through the programme are important in desistance from crime (Bryne and Trew, 2008). Being a part of a group is also identified in the GLM as a primary good (Willis et al., 2013). The participants' narratives indicate that the programme acts as a secondary good allowing to attain the primary good of being a part of a group.

Will discussed other participants in relation to what they have experienced:

"some people that come from other countries, but some of their countries and that, they've come over here from proper proper hardship and I don't mean just struggling for money, I mean war-torn countries and all that. So it's good when you see them working, because at least they've got a life if 
you know what I mean. Some countries where their families have been shot to death and everything, you know it's like wow, it's weird" (Line 267-271)

It can be viewed through participants' narratives such as Wills that the aspect of the programme not solely being aimed at individuals with a criminal history is of importance to the participant. It can be viewed that through the participants working with other people from different backgrounds, a greater sense of support and empathy is encouraged.

\section{Limitations}

Purposive sampling by the programme coordinator was used to recruit participants. This may have resulted in a biased selection process, in which the programme coordinator identified pro-social, motivated individuals that would discuss the programme in a positive manner. Also, it is recognised that individuals who actively participate in such programmes differ from those who drop out (Bushway and Apel, 2012). The individuals that did not engage for the duration of the programme did not participate in the research therefore their different experiences are not accounted for. A further limitation of this research is that the primary researcher had previously had an active role in the programme, involving providing support and assistance to the participants. Through this previous involvement and knowledge of the programme, the likelihood of a subjective analysis and interpretation is increased.

\section{Future suggestions}

The sample of this research consisted entirely of individuals that actively participated in the programme. Future research should also include participants with criminal histories that did not engage with the programme for its duration. This would allow the differences in the experiences of those who actively engaged and those who dropped-out to be examined. This would provide a beneficial foundation to understanding why the programme did not work for those who dropped out and the improvements that could be implemented to support their needs. Furthermore, as it was indicated by participants that the programme being inclusive of people from other backgrounds was important to their experience, and this is an under-researched area, it would be beneficial for this to be explored further.

\section{Conclusion}

This research captured individuals with criminal histories experiences of participating in a life skills and work readiness programme. The programme supported the achievement of primary goods identified in the GLM (Ward, 2002). This includes skills for excellence in work, a sense of community, as well as future orientated secondary goods. The participants' narratives reflected the importance of an identity shift from an offender to a member of the community. This identity shift can be viewed as a result of changing commitments and the resultant ways of life (Ward and Brown, 2004). This supports that developing a new pro-social identity is crucial to the desistance journey (Maruna, 2001). A further crucial aspect of desistance identified was the role of social integration, this was reflected in the importance of belonging to the group and community. This supports the primary good of a need to be part of a community (Willis et al., 2013), In summary, the programme promoted pro-social ways of achieving ways of primary goods, which then facilitated desistance. This research identifies the positive impact of community life skills and work-readiness programmes for individuals with a criminal history, and that such a programme appears to support desistance from crime. 


\section{Implications for practice}

- Individuals with a criminal history perceive a "need for change" and following this, it is likely that they will participate in opportunities to facilitate this change

- The community was integral in the participants positive experience. The benefits of individuals with a criminal history participating in generative activities should be further explored

- Participants placed importance on a sense of belonging, and working alongside other participants from different backgrounds. An understanding of the impact of programmes that are not specifically offender-focused on the desistance process would be beneficial

- The programme allowed individuals to develop skills and create new identities for themselves, supporting the Good Lives Model

\section{References}

Aresti, A., Eatough, V. and Brooks-Gordon, B. (2010), "Doing time after time: An Interpretative Phenomenological Analysis of reformed ex-prisoners' experiences of self-change, identity and career opportunities", Psychology, Crime \& Law, Vol. 16 No. 3, pp. 169-190.

Best, D., Musgrove, A. and Hall, L. (2018), "The bridge between social identity and community capital on the path to recovery and desistance", Probation Journal, Vol 65 No.4 pp. 394-406.

Bryne, C. and Trew, K. (2008), "Pathways Through Crime: The Development of Crime and Desistance in the Accounts of Men and Women Offenders", The Howard Journal of Crime and Justice, Vol. 47 No. 3, pp. 238-258.

Bushway, S. and Apel, R. (2012), "A Signaling Perspective on Employment-Based Reentry Programming", Criminology \& Public Policy, Vol. 11 No. 1, pp. 21-50.

Cherney, A., and Fitzgerald, R. (2016), "Finding and Keeping a Job: The Value and Meaning of Employment for Parolees", International Journal of Offender Therapy and Comparative Criminology, Vol. 60 No. 1, pp. 21-37.

Department of Work and Pensions (DWP) and the Ministry of Justice (MOJ) (2016), "Written evidence from the Department for Work and Pensions and the Ministry of Justice (SEO0033)", available at:

http://data.parliament.uk/writtenevidence/committeeevidence.svc/evidencedocument/work-andpensions-committee/support-for-exoffenders/written/32170.pdf [Accessed on the $10^{\text {th }}$ September 2017].

Ellemers, N., Spears, R. and Doosje, B. (2002), "Self and Social Identity", Annual Review of Psychology, Vol. 53 No. 1, pp. 161-186.

Fortune, C., Ward, T. and Willis, G. (2012), "The Rehabilitation of Offenders: Reducing Risk and Promoting Better Lives", Psychiatry, Psychology and Law, Vol. 19 No. 5, pp. 646-661.

Ford, R., Willmot, A., Hagan, S. and Hoven, H. (2015), Labour market integration of disadvantaged people: Analysis of the Business in the Community Ready for Work Programme in the United Kingdom. London: Business in the Community. [Online] [Accessed on 15 $5^{\text {th }}$ June 2017] 
Giordano, P., Cernkovich, S. and Rudolph, J. (2002), "Gender, Crime, and Desistance: Toward a Theory of Cognitive Transformation", American Journal of Sociology, Vol. 107 No. 4, pp. 990-1064.

HM Government (2005), 'Reducing Re-Offending Through Skills and Employment' Available at: https://www.gov.uk/government/uploads/system/uploads/attachment data/file/272207/6702.pdf [Accessed on 8th April 2017].

Kirby, A. (2016), "Is Volunteering for everyone? Volunteering opportunities for young ex-offenders", Safer Communities, Vol. 15 No. 2, pp. 82-93.

Laub, J. H., and Sampson, R, J. (2003), Shared beginnings, divergent lives: Deliquent boys to age 70, Harvard University Press, Cambridge.

LeBel, T., Burnett, R., Maruna, S. and Bushway, S. (2008) "The 'Chicken and Egg' of Subjective and Social Factors in Desistance from Crime". European Journal of Criminology, 5(2) pp.131-159.

Maruna, S. (2001), Making good: how ex-convicts reform and rebuild their lives, American Psychological Association, Washington, D.C.

Maruna, S. and LeBel, T. (2003), "Welcome Home? Examining the "Reentry Court" Concept from a Strengths-based Perspective", Western Criminology Review, Vol. 4 No.2, pp.91-107.

McNeill, F., Batchelor, S., Burnett, R. and Knox, J. (2005) "21st century social work: reducing reoffending - key practice skills" Social Work Inspection Agency, Glasgow. Available at:

http://strathprints.strath.ac.uk/38070/1/21st_c.pdf [Accessed on 3rd April 2017]

Ministry of Justice (2013), "Transforming Rehabilitation: A Strategy for Reform" Available at: https://consult.justice.gov.uk/digital-communications/transformingrehabilitation/results/transforming-rehabilitation-response.pdf [Accessed on 20 ${ }^{\text {th }}$ January 2019]

Ministry of Justice and National Statistics (2019) "Proven reoffending statistics quarterly bulletin, July 2017 to September 2017" Available at:

https://assets.publishing.service.gov.uk/government/uploads/system/uploads/attachment data/file 1820356/proven reoffending bulletin July to Sept 17.pdf [Accessed on 20th August 2019]

Newton, D., Day, A., and Giles, M. (2018) "The Impact of Vocational Education and Training Programs on Recidivism: A Systematic Review of Current Experimental Evidence", International Journal of Offender Therapy and Comparative Criminology, Vol. 62 No. 1, pp 187- 207

Paternoster, R. and Bushway, S. (2009), "Desistance and the Feared Self: Toward an Identity Theory of Criminal Desistance", Journal of Criminal Law and Criminology, Vol. 99 No. 4, pp. 1103-1152.

Prison Reform Trust (2018) "Prison: the facts. Bromley Briefings Summer 2018" Available at: http://www.prisonreformtrust.org.uk/Portals/0/Documents/Bromley\%20Briefings/Summer\%20201 8\%20factfile.pdf [Accessed on $20^{\text {th }}$ January 2019]

Richie, B. (2001) "Challenges Incarcerated Women Face as They Return to Their Communities: Findings from Life History Interviews", Crime and Delinquency, Vol. 47, pp 368-389

Smith, A, J. and Osborn, M. (2007), "Interpretative Phenomenological Analysis". In Smith, A, J. (ed), Qualitative Psychology: A Practical Guide to Research Methods, 2nd ed, SAGE Publications Ltd, London, pp 53-80.

Smith, J., Flowers, P. and Larkin, M. (2009), Interpretative phenomenological analysis, Sage, London. 
Talbot, E., Völlm., and Khalifa, N. (2017), "Effectiveness of work skills programmes for offenders with mental disorders: A systematic review", Criminal Behaviour and Mental Health, Vol. 27 No. 1, pp. 40 -58 .

Terry, C. (2003), The Fellas: Overcoming Prison and Addiction, Wadsworth/Thomson Learning, Belmont.

Uggen, C., Manza, J. and Behrens, A. (2004), "Less than an average citizen': Stigma, role transition and the civic reintegration of convicted felons" In Maruna, S. and Immarigeon, R. (Ed), After crime and punishment: Pathways to offender reintegration. Willan Publishing, UK, pp. 261-293.

Visher, A., Winterhead, L., and Coggeshall, M. (2005) "Ex-offender employment programs and recidivism: A meta-analysis", Journal of Experimental Criminology, Vol. 1 pp 295- 315.

Ward, T. (2002), "Good lives and the rehabilitation of offenders", Aggression and Violent Behavior, Vol. 7 No. 5, pp. 513-528.

Ward, T. and Brown, M. (2004), "The good lives model and conceptual issues in offender rehabilitation", Psychology, Crime \& Law, Vol. 10 No. 3, pp.243-257.

Ward, T. and Maruna, S. (2007), Rehabilitation: Beyond the risk paradigm, Routledge, London.

Willis, G., Prescott, D. and Yates, P. (2013), "The Good Lives Model (GLM) in Theory and Practice", Sexual Abuse in Australia and New Zealand, Vol. 5 No. 1, pp.3-9. 